\title{
Design of a Miniaturized Implantable PIFA with DGS for the Investigation of Uterus Fibroids
}

\author{
Mousume Samad \\ Md. Mostafizur Rahman
}

Department of Electronics and Communication Engineering, Khulna University of Engineering \& Technology, Khulna, Bangladesh

\section{S. M. Shamim}

Department of Information and Communication Technology, Mawlana

Bhashani Science and Technology University, Dhaka, Bangladesh

Doi:10.19044/esj.2021.v17n37p211

Submitted: 12 August 2021

Accepted: 20 September 2021

Published: 31 October 2021
Copyright 2021 Author(s)

Under Creative Commons BY-NC-ND 4.0 OPEN ACCESS

Cite As:

N’Guessan A.H., Gogoue D.O., Anougba B.D., Dembélé I. \& Allou K. (2021). Evaluation de Différents Types de Substrats sur Le Développement des Plantules de Palmiers À Huile (Elaeis Guineensis Jacq.) en Côte d'Ivoire. European Scientific Journal, ESJ, 17(37), 211. https://doi.org/10.19044/esj.2021.v17n37p211

\section{Abstract}

Continuous follow-up of unusual fibroids growth in the uterus is critical for minimizing the unwanted complexities of female's certain health conditions. This article presents an implantable circular-shaped multi-facet PIFA for early detection of uterus fibroids. The radius of the circular antenna is $7.5 \mathrm{~mm}$ with the dimension of $\pi \times(7.5)^{2} \times 1.58 \mathrm{~mm}^{3}$. The antenna has maximum return loss of $37 \mathrm{~dB}$ at $2.43 \mathrm{GHz}$, is suitable for ISM band use. Being low profile makes it entirely implantable in uterus. To expand the radiation efficiency and enhance the bandwidth two dielectric substrates of FR-4 and Rogers RO 3210 with each thickness of $0.79 \mathrm{~mm}$ are utilized. Top and bottom sides of the antenna have covered with Teflon to ensure biocompatibility. Defected ground structure has been used for size reduction as well as bandwidth increase. The performance of the antenna is also investigated in free space, biocompatible layer, and uterus layer. The estimated specific absorption rate is $0.36 \mathrm{~W} / \mathrm{kg}$ when implanted in uterus. 
Keywords: PIFA (Planner Inverted-F Antenna), Industrial, Scientific, and Medical (ISM) Bands, DGS (Defected Ground Structure), Specific Absorption Rate (SAR)

\section{Introduction}

Uterine fibroids are amiable tumors that begin in the uterus. Enormous fibroids may cause excessive bleeding because fibroids may create iron inadequacy frailty (Uterine, 2020). That's why the early detection process may control the abnormal growth of fibroids. For this, some techniques include Ultrasound, Magnetic resonance imaging (MRI), Hysterosonography, Hysteroscopy, etc. have been used for the detection of fibroids (Uterine Fibroids, 2020). However, traditional ultrasound doesn't provide accurate size information and the MRI process is expensive. Besides Hysterosonography, Hysteroscopy is painful to patients for continuous fibroid monitoring. Subsequently, Implantable medical devices (IMDs) play a vital role in various medical applications including monitoring during this COVID-19 pandemic period. For this monitoring system, an antenna is one of the major parts of IMD that should be implemented into the patient's body (Soliman, 2021). The deployment of an implantable antenna can offer two advantages, the first one is the mobility of the patient, and the second one is the location independent monitoring facility that focuses on real-time monitoring (Shokry, 2013).

Several types of antennas have been recommended in the literature for such applications. These are slotted antenna, microstrip antenna, and planer inverted-F antenna (PIFA). However, miniaturization of these antennas is a key challenge to make them applicable in implantable medical devices. There are various reasons for the selection of PIFA antenna (Azzaz, 2021). By connecting only a shorting pin between the patch and the ground, a simple micro patch antenna can be converted to a PIFA antenna (Al-Faruk, 2019 and Wong, 2004) helps to miniaturize. Moreover, different strategies can be applied to reduce the dimension of the antenna and to enhance the performance. For instance, the meandering technique in PIFA can reduce the size of the antenna and can improve the RF performance. Meandering in PIFA can likewise provide a more current conduction path (Ali, 2017).

It can be observed that the resonant frequency of the antenna is significantly lowered by inserting slots in the antenna's ground plane, which can lead to a large antenna size reduction for a fixed frequency operation and increase bandwidth (Nawale, 2014). It is regarded as defected ground structure (DGS).

According to the Federal Communications Commission (FCC), various frequencies are assigned for medical implants. Usually, the medical implant communications service (MICS) is allocated a band (402-405 MHz) 
for the implantable medical devices. The industrial, scientific, and medical (ISM) bands (433-434.8 MHz, 902-928 MHz, 2.4-2.48 GHz) and the wireless medical telemetry services (WMTS) band (1395-1400 MHz) have also been suggested for the implantable medical devices (Guo, 2017). These bands provide a wide frequency range for biomedical applications. However, the ISM band has been more suitable for biomedical applications due to its highfrequency bandwidth (Sinha, 2021). Compare to others, the ISM band allows making the wavelength smaller as well as obtain a higher bit rate after implantation and assists the biotelemetry system (Islam, 2016).

For avoiding different side effects of an implantable antenna in the human body, a biocompatible layer can be used. A PIFA antenna coated with a biocompatible material helps to minimize the side effects on the surrounding tissues (Singh, 2021). Additionally, this coating can prevent toxic reactions or effects or protect from any injury in the human tissues. Therefore, biocompatible material ensures the protection of the adverse environment in a complex uterus layer from radiation (Merli, 2011). Hence, the important factors to design an implantable antenna like miniaturization, bandwidth requirement, radiation efficiency, and performance of the antenna in free space, biocompatible layer, and uterus layer should be analyzed.

Different types of implantable antennas have been designed by many researchers for biomedical applications such as circular PIFA, Multilayer dipole antenna, slot PIFA antenna, Archimedean spiral PIFA, etc. (Islam, 2018). For instance, (Ali, 2017) proposed a circular-shaped Planner inverted$\mathrm{F}$ antenna resonates at $2.45 \mathrm{GHz}$ in ISM band having a dimension of $\pi^{*}(8.5)^{2 *} 1.5$ for implantable application inside Biological Phantom Design with about bandwidth of 47.4MHz. In another study, (Hossain, 2017) designed a compact triple-band PIFA antenna of size $10 \mathrm{~mm} \times 10 \mathrm{~mm} \times 1.5 \mathrm{~mm}$ for implantable application inside voxel model that operates at medical (ISM) band $915 \mathrm{MHz}$, wireless medical telemetry service (WMTS) band $1.43 \mathrm{GHz}$, and ISM band $2.45 \mathrm{GHz}$.

Besides, a miniature multilayer Archimedean spiral PIFA antennas with a volume of design are less than $60 \mathrm{~mm}^{3}$ (Kumar, 2019). The antenna resonates at MICS (402-405MHz) and ISM Band (433-435MHz) in human body tissue models. Implantable compact PIFA antenna with a slot-less ground plane which reduces the design complexity and operates in ISM band range of Human Body Model is constructed by (Miran, 2019). Moreover, (Sultana, 2017) proposed a rectangular-shaped Implantable PIFA antenna with a dimension of $12.5 \times 12.5 \mathrm{~mm}^{2}$ inside the Brain, Breast, and Muscle of a Human Phantom Model that provides resonant frequency at $404 \mathrm{MHz}$. The maximum return loss of the antenna is $25 \mathrm{~dB}$. On the other hand, a compact circular stacked implantable dipole antenna with a dimension of $\pi *(10)^{2} * 2.8$ $\mathrm{mm}^{3}$ is proposed for the ISM band. This antenna resonates at $915 \mathrm{MHz}$ and 
the $10 \mathrm{~dB}$ impedance bandwidth of $10 \mathrm{MHz}$ in a three-layer human body model to verify the feasibility of implant (Hosain, 2012).

In this paper, a multi-facet circular shape meandered PIFA is designed and simulated for implantable medical applications. The design of the antenna and its performance in free space has been presented in Section II. The design of the uterus phantom model has been shown in Section III. This section also includes the performance of the antenna with a biocompatible layer in the uterus layer model. Section IV provides the calculation of the specific absorption rate (SAR), Section V remarks the comparison between several environment and different antennas. Finally, the Conclusion of the work is highlighted in Section VI.

\section{Antenna Design}

\section{A. Configuration of Miniaturized implantable Antenna}

The proposed multilayer circular meandered PIFA at a resonance frequency of $2.4 \mathrm{GHz}$ is designed using XFDTD software. The circular shape is used as it is easy to implant and it does not damage surrounded tissues. The antenna dimension is $\pi *(7.5)^{2} * 1.58 \mathrm{~mm}^{3}$. A geometrical value of the purposed circular PIFA for the top view and the bottom view is shown in Fig. 1(a) and Fig. 1(b) respectively. The proposed antenna was constructed with conducting meandered patch, a substrate, and ground with DGS. In this design, the substrate has been embedded between the patch and ground. To increase the radiation efficiency, two-layer dielectric substrates namely FR-4 and Rogers RO 3210 are used which have dielectric constants $\left(\varepsilon_{\mathrm{r}}\right)$ of 4.3 and 10.2 respectively; and loss transients $(\delta)$ of 0.025 and 0.003 respectively. The height of the antenna is $1.58 \mathrm{~mm}$ while each side of the dielectric substrate is $0.79 \mathrm{~mm}$ thick. The radius of the substrate is $7.5 \mathrm{~mm}$. The meandering technique is used to miniaturize the antenna. The width of the meandered line is $1 \mathrm{~mm}$. One layer is connected with another layer by a conductive shorting pin. DGS has been achieved by cutting a slot of plus-shaped configuration on the ground plane. This defect disturbs the current distribution in the ground plane and assists control with contributing impedance and excitation of radio waves in the substrate. The ground defect has been varied to achieve the optimum performance. The antenna needs to keep in the biocompatible layer to achieve compatibility. The biocompatible material Teflon (dielectric constant $\varepsilon_{\mathrm{r}}=2.25$, loss transient $\delta=0.0001$ ) with a thickness of $0.1 \mathrm{~mm}$ has been covered to the antenna both top and bottom layer so that the radiation of the antenna does not cause a toxic effect in the tissues. The coaxial feeding technique is used to obtain simulation results. Matching is required between the feed line and the antenna to get maximum energy transmission and reception. The feeding location is important to match the impedance of the PIFA. The antenna input impedance depends on the location of the feed line 
with respect to the shorting pin. The side view of the antenna has appeared in Fig. 2 and the measurement of its constituents is mentioned in Table I.

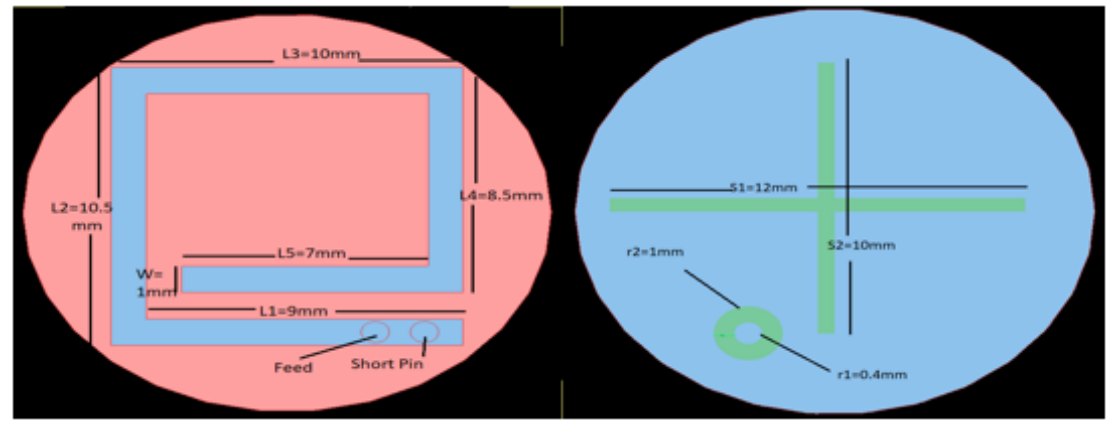

(a)

(b)

Fig. 1. Geometry of proposed Antenna (a) Top Layer (b) Bottom Layer

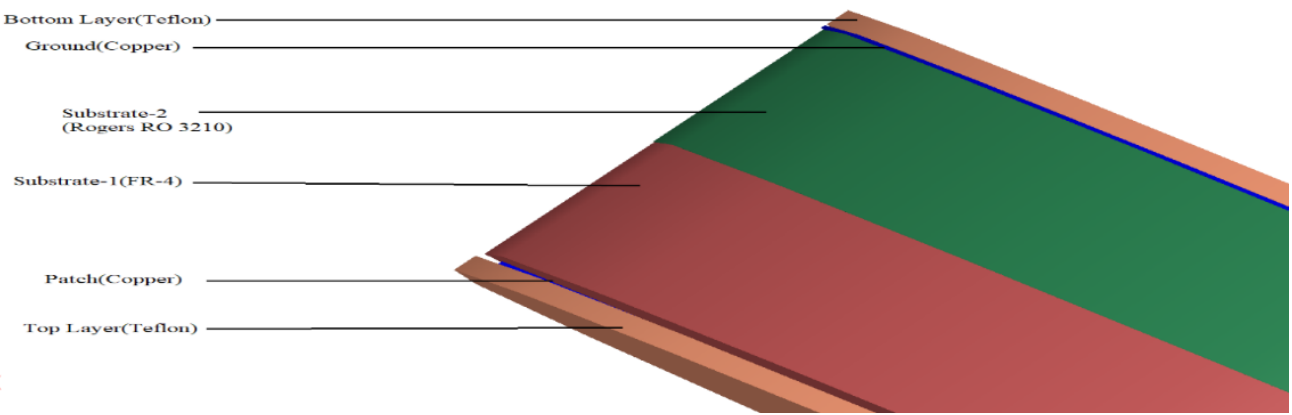

Fig. 2. Orientation of different layers in proposed antenna

Table I. Geometrical Dimension Of The Proposed Antenna

\begin{tabular}{|c|c|c|}
\hline Parameter & Material & Value(mm) \\
\hline Substrate & $\begin{array}{l}\text { Laye1: FR-4 ;Layer } \\
\text { 2: Rogers RO } 3210\end{array}$ & $\begin{array}{c}\text { Radius: } 7.5 \mathrm{~mm} \text {; } \\
\text { Thickness for Layer } 1=0.79 \mathrm{~mm} \text {; Thickness } \\
\text { for Layer } 2=0.79 \mathrm{~mm}\end{array}$ \\
\hline Patch & Copper & $\begin{array}{l}\mathrm{L} 1=9 \mathrm{~mm} ; \mathrm{L} 2=10.5 \mathrm{~mm} ; \mathrm{L} 3=10 \mathrm{~mm} ; \\
\text { L4=8.5mm; L5=7mm; W=1mm; } \\
\text { Thickness }=0.01778 \mathrm{~mm}\end{array}$ \\
\hline Feed Line & Copper & $\begin{array}{c}\text { Inner Radius r1:0.4mm; Outer Radius } \\
\text { r2:1mm }\end{array}$ \\
\hline $\begin{array}{l}\text { Biocompatible Top } \\
\text { layer and bottom layer }\end{array}$ & Teflon & Radius:7.5mm ,Thickness $=0.1 \mathrm{~mm}$ \\
\hline Shorting Pin & Copper & Radius:0.4mm. \\
\hline Ground with DGS & Copper & Radius:7.5mm;S1=12mm;S2=10mm \\
\hline
\end{tabular}

The step-by-step design procedures of the proposed antenna are shown in the flow chart 


\section{Design Requriments}

Resonant frequency, materials (relative permitivity and loss trangent), and thickness of substrate, patch and ground.

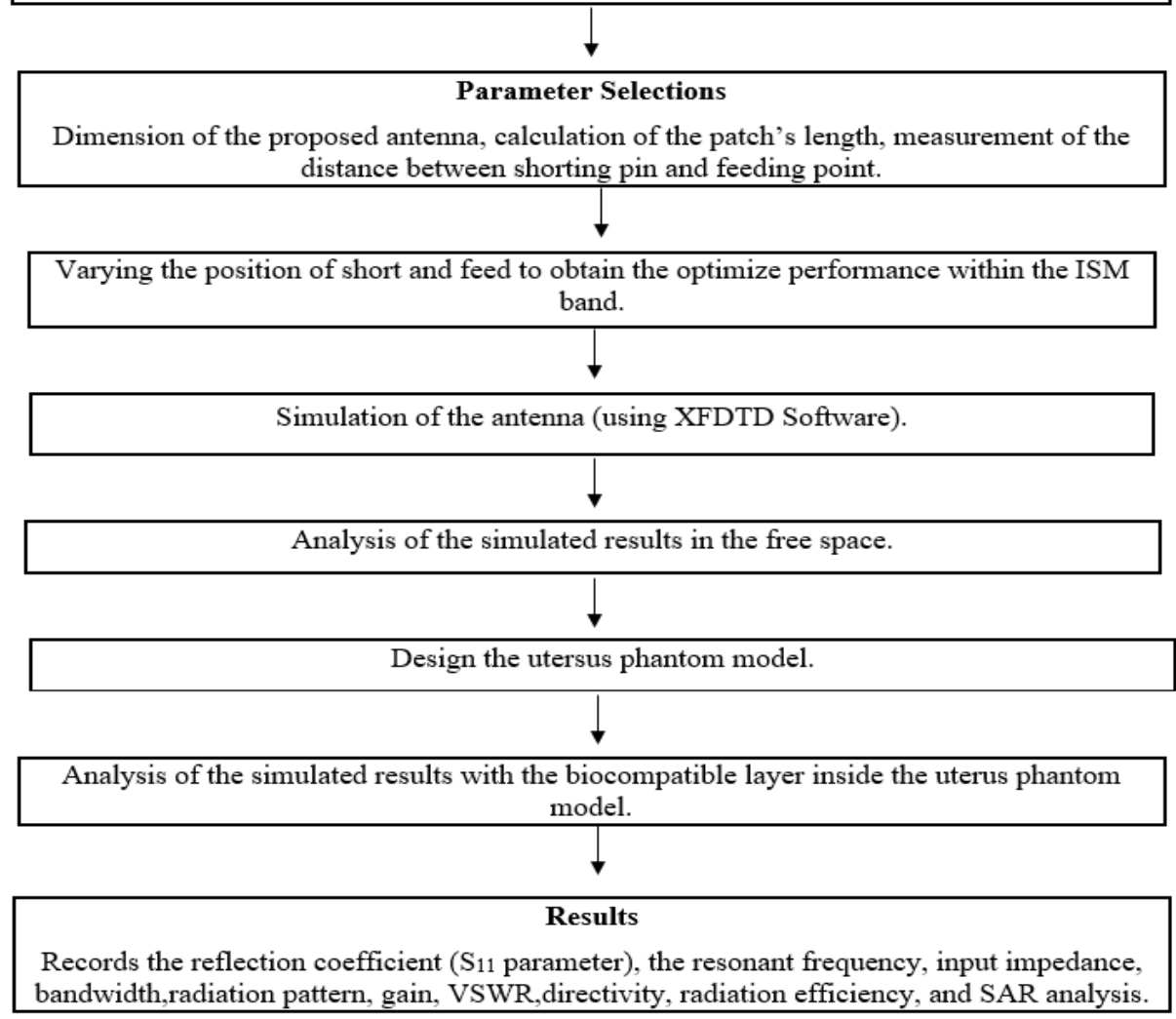

Fig. 3. Flow chart of the proposed antenna

\section{B. Simulation result in free space}

Starting with free space analysis, the antenna parameters including resonant Frequency, $\mathrm{S}_{11}$, VSWR, Radiation Efficiency, Maximum Gain, Bandwidth, etc. have been studied. The antenna is optimized using the basic trial and error method while basis provided from the study of the surface current distribution.

The reflection coefficient $\left(\mathrm{S}_{11}\right)$ of the proposed multi-facet with DGS PIFA antenna in free space has been shown in Fig. 4. It implies that the antenna resonates at $2.43 \mathrm{GHz}$ which lies in the ISM band. The lowest magnitude of $\mathrm{S}_{11}$ parameters is also $-37 \mathrm{~dB}$. Fig. 5 plots simulated input impedance of the proposed antenna. The input impedance of the designed antenna in free space is $48.946-0.347 \mathrm{i} \Omega$ at $2.43 \mathrm{GHz}$. The bandwidth of the proposed antenna in free space is $56.7 \mathrm{MHz}$. The gain and directivity in free space are found $12.521 \mathrm{dBi}$ and $6.5555 \mathrm{dBi}$ respectively. The 2D which includes both E-plane 
and H-plane patterns and 3D radiation has been shown in Fig. 6(a) and Fig. 6 (b). The radiation efficiency is $1.24 \%$ and VSWR has been 1.077 at resonant frequency.

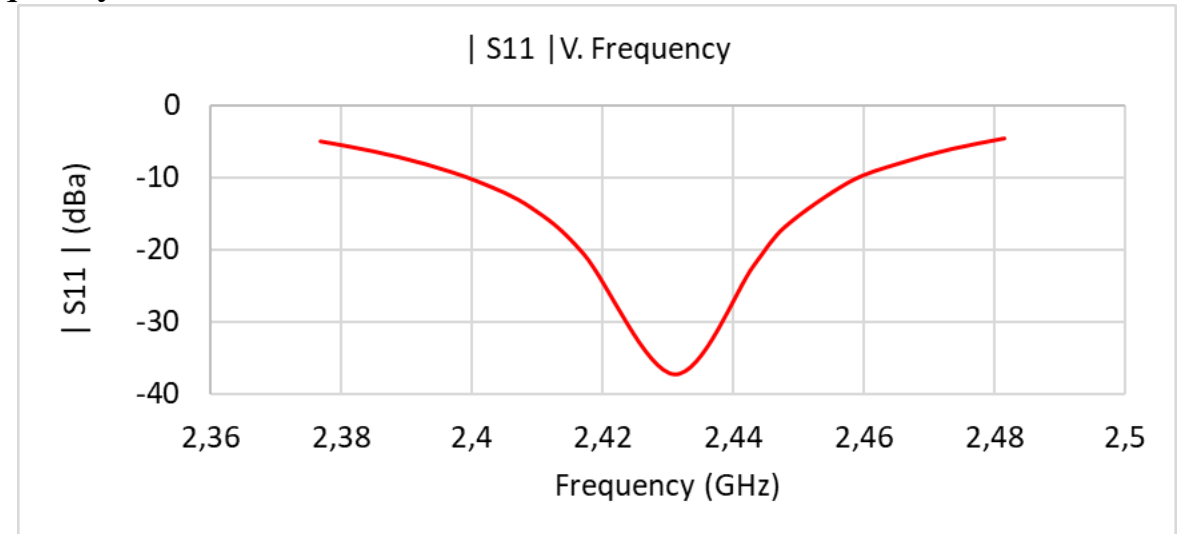

Fig. 4. The reflection coefficient of proposed antenna in free space

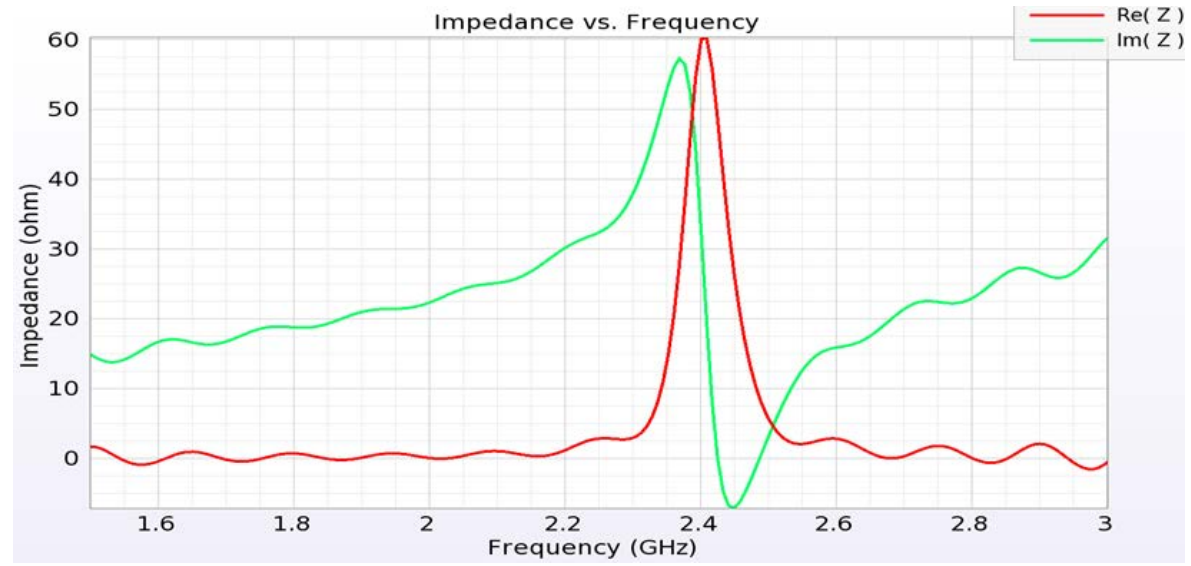

Fig.5. Input impedance versus frequency of the designed antenna

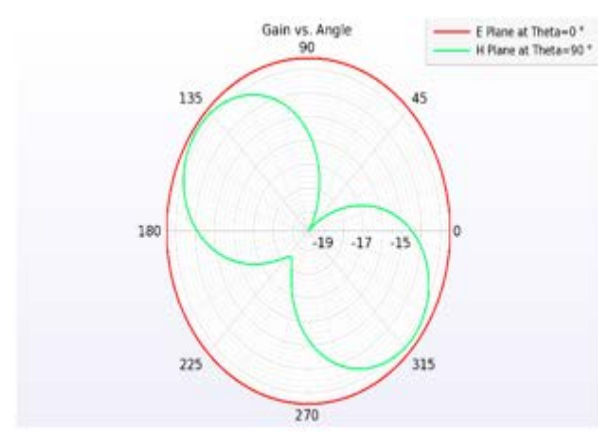

(a)

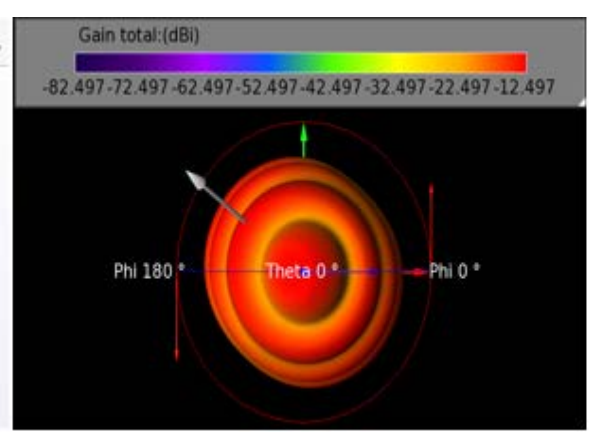

(b)

Fig.6. Antenna in free space

a) 2D radiation pattern of the antenna b) 3D radiation pattern of the antenna 


\section{Phantom Model Of Uterus}

\section{A. Uterus phantom model design}

The human uterus is a pear-shaped muscular organ. The standard dimensions of the Normal uterine are $7.6 \times 4.5 \times 3 \mathrm{~cm}^{3}$ (Parmar, 2016). No pregnant uterine size shifts with age, number of pregnancies, and patient endocrinological status. Ordinary grown-up uterus measures around 7.2$9.0 \mathrm{~cm}$ long, $4.5-6.0 \mathrm{~cm}$ wide what's more, $2.05-3.5 \mathrm{~cm}$ deep (Parmar, 2016). The uterine wall has been constructed with three layers from innermost to outermost are endometrium, myometrium, and perimetrium respectively. Using the 3-layer rectangular, the characteristic of the designed antenna has also been investigated. Table II represents the dielectric properties of these three-layer tissues which are used in this simple rectangular model (Density, 2020), (Dielectric, 2020). The dimension of this model is $80 \mathrm{~mm} \times 50 \mathrm{~mm} \times$ $30 \mathrm{~mm}$. This model consists of three different tissues including endometrium, myometrium, and perimetrium. The thicknesses of the endometrium, myometrium, perimetrium are $3 \mathrm{~mm}, 5 \mathrm{~mm}$, and $0.5 \mathrm{~mm}$ respectively (Andolf, 1996), (Person, 2020), (Wei, 2015). The antenna is embedded into this phantom model as shown in Fig.7.In this condition, the antenna characteristics are analyzed.

Table II. Dielectric Properties Of The Three Layer Uterus Model [19-23]

\begin{tabular}{|l|c|c|c|c|}
\hline Layer Name & Thickness & Permittivity & $\begin{array}{l}\text { Conductivity } \\
(\mathbf{s} / \mathbf{m})\end{array}$ & $\begin{array}{l}\text { Mass } \\
\text { Density(kg/m } \mathbf{3})\end{array}$ \\
\hline Endometrium & $3 \mathrm{~mm}$ & 52.7667 & 1.5134 & 1078 \\
\hline Myometrium & $5 \mathrm{~mm}$ & 52.7 & 1.74 & 1090 \\
\hline Perimetrium & $0.5 \mathrm{~mm}$ & 43.1 & 1.68 & 1027 \\
\hline
\end{tabular}

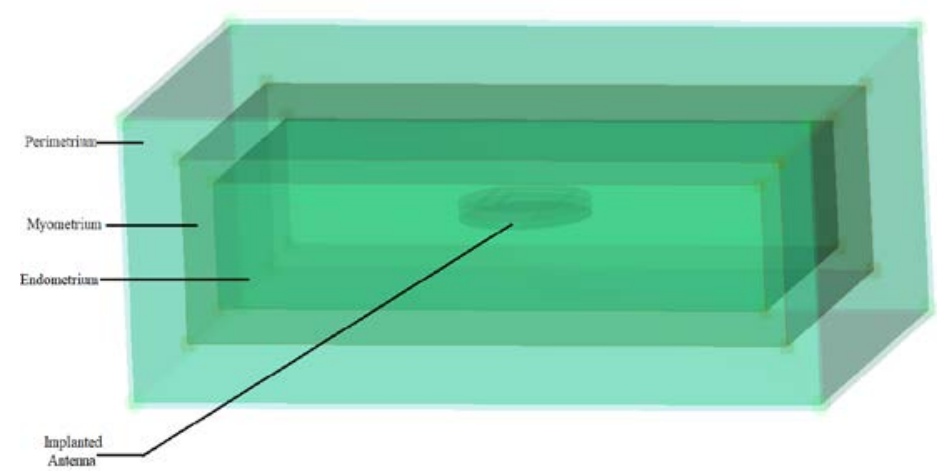

Fig.7. The Proposed Uterus phantom model

\section{B. Simulation result in Phantom model (with biocompatible layer)}

The reflection coefficient of the proposed multi-facet with DGS PIFA antenna with biocompatible layer and inside uterus layer has been shown in 
Fig.8. The antenna resonates at $2.44 \mathrm{GHz}$ with a reflection coefficient of -21 $\mathrm{dB}$ when the antenna coated with the biocompatible material.

The antenna with biocompatible material coating has been inserted in the uterus phantom model. Now, the antenna resonates at $2.43 \mathrm{GHz}$ of lowest magnitude $S_{11}$ parameter is $-26 \mathrm{~dB}$. The bandwidth of the proposed antenna in the biocompatible layer and the uterus phantom model is $48.3 \mathrm{MHz}$ and 61.2 $\mathrm{MHz}$ respectively.

| S11 |V. Frequency

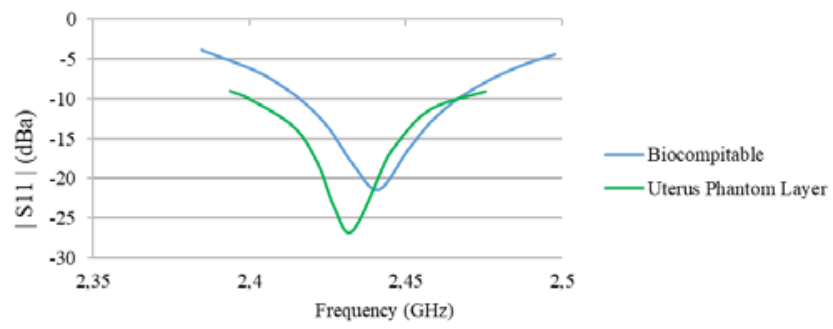

Fig.8. The reflection coefficient of proposed antenna in biocompatible layer and uterus model layer

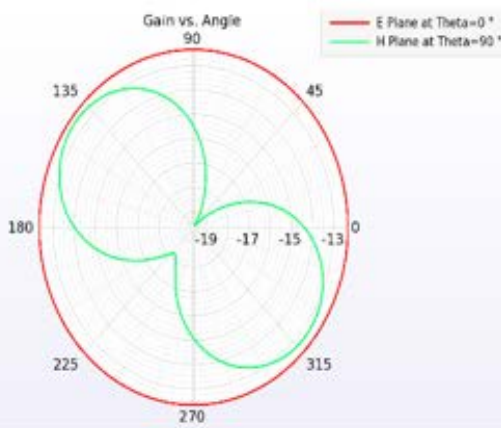

(a)

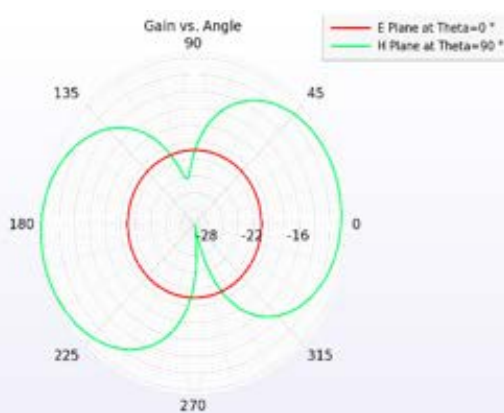

(c)

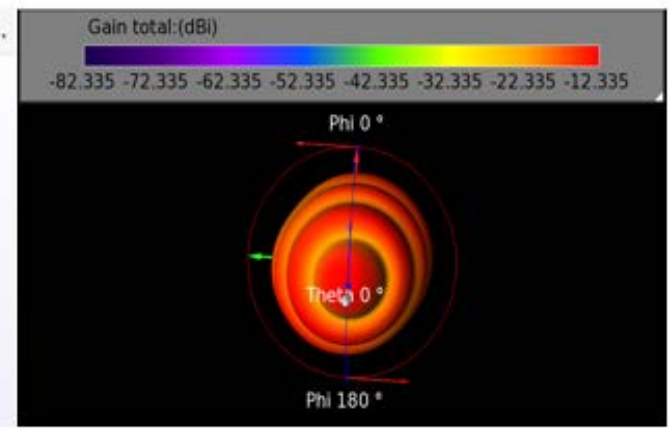

(b)

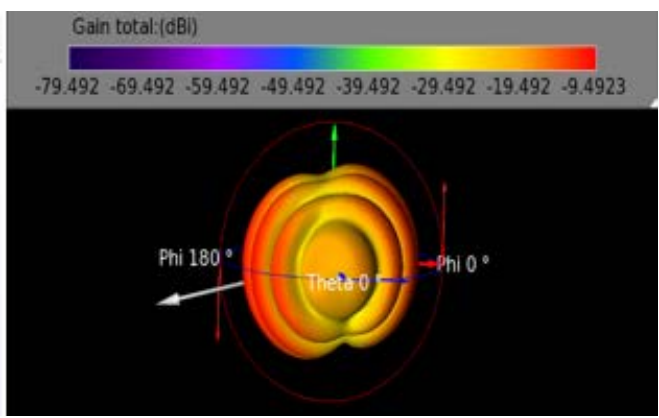

(d)

Fig.9. Radiation pattern of the antenna (a) 2D radiation pattern inside biocompatible layer, (b) 3D radiation pattern inside biocompatible layer, (c) 2D radiation pattern inside uterus phantom model, and (d) 3D radiation pattern inside uterus phantom model 
Fig.9 shows the 2D and 3D radiation patterns of the proposed antenna in the biocompatible layer and uterus phantom model. In the biocompatible layer, the gain and directivity are $-12 \mathrm{dBi}$ and $6.7 \mathrm{dBi}$ respectively. The gain and directivity are $-9.5 \mathrm{dBi}$ and $8.9 \mathrm{dBi}$ respectively have been observed in the uterus phantom layer. Besides, the radiation efficiency and VSWR in the biocompatible layer are $1.30 \%$ and 1.175 respectively. Finally, the radiation efficiency and VSWR are $1.46 \%$ and 1.098 respectively when the antenna is placed in the uterus model layer.

\section{Sar Analysis}

Specific Absorption Rate (SAR) is related to patient safety. The surrounding tissues absorbed the electromagnetic power that should be calculated to assess the safety requirement of implanted antenna (RF Safety, 2020). The Specific absorption rate (SAR) is measured at 2. $43 \mathrm{GHz}$ by absorbing the energy through the layer of the uterus. The SAR value for $1 \mathrm{~g}$ averaged is $0.355464 \mathrm{~W} / \mathrm{kg}$ which passes the safety requirements. The maximum local SAR value is $142.5 \mathrm{~W} / \mathrm{kg}$ when $1 \mathrm{~W}$ power is delivered to the proposed antenna. Therefore, the implant antenna should not excited with more than $2.49 \mathrm{~mW}$ power to satisfy the safety regulation. Fig.10 (a) and (b) demonstrates the cloud plot and line plot of the SAR (W/Kg) respectively.

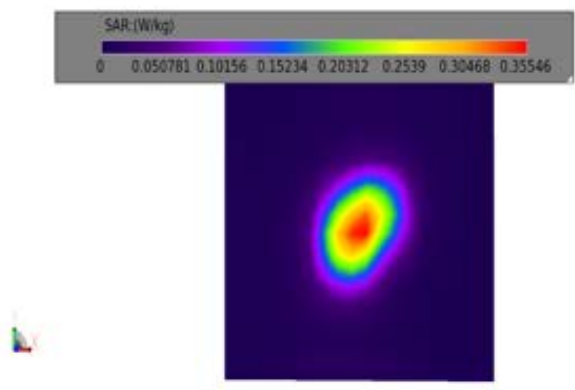

(a)

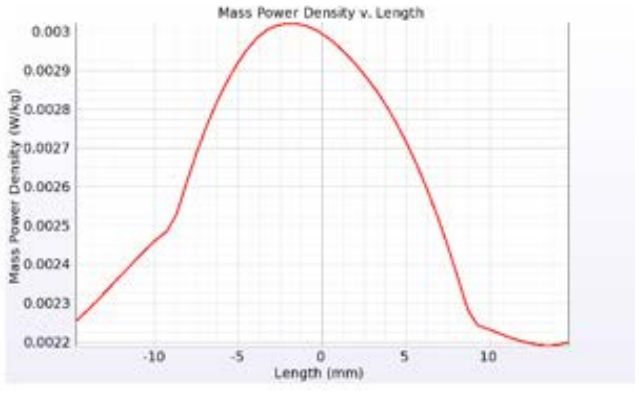

(b)

Fig. 10. Maximum SAR (W/Kg) value inside uterus Phantom model (a) Cloud plot (b) Line plot

\section{Comparison}

To obtain a clear view of the proposed antenna's performance the comparison between three cases are presented. Some important parameters like reflection coefficient, VSWR at the resonant frequency, radiation efficiency, maximum gain, directivity, radiation pattern, bandwidth, etc. can be considered to evaluate the suitability of the implantable antenna. The comparison between these parameters in free space, inside the biocompatible layer, and in the uterus model layer are presented in Table III.

The proposed antenna are comparable with the other presented antennas for the similar application as shown in Table IV. 
Table III. Comparative Analysis Of The Antanna In Free Space, Inside The Biocompitable Layer, And Inside The Uterus Model

\begin{tabular}{|c|c|c|c|}
\hline Parameters & $\begin{array}{c}\text { Antenna in } \\
\text { Free Space }\end{array}$ & $\begin{array}{c}\text { Antenna inside } \\
\text { Biocompatible } \\
\text { Layer }\end{array}$ & $\begin{array}{c}\text { Antenna inside } \\
\text { the Uterus Phantom }\end{array}$ \\
\hline $\mathrm{S}_{11(\mathbf{d B})}$ & -37.194 & -21.4288 & -26.6348 \\
\hline $\begin{array}{c}\text { Impedance } \\
\text { Bandwidth }\end{array}$ & $56.73 \mathrm{MHz}$ & $48.34 \mathrm{MHz}$ & $61.24 \mathrm{MHz}$ \\
\hline $\begin{array}{c}\text { Resonant } \\
\text { Frequency }\end{array}$ & $2.431 \mathrm{GHz}$, & $2.44126 \mathrm{GHz}$ & $2.4329 \mathrm{GHz}$ \\
\hline $\begin{array}{c}\text { VSWR at } \\
\text { Resonant } \\
\text { Frequency }\end{array}$ & 1.077 & 1.175 & 1.098 \\
\hline $\begin{array}{c}\text { Radiation } \\
\text { Efficiency (\%) }\end{array}$ & $1.24 \%$ & $1.30 \%$ & $1.46 \%$ \\
\hline Maximum Gain & $-12.521 \mathrm{dBi}$ & $-12.335 \mathrm{dBi}$ & $-9.4923 \mathrm{dBi}$ \\
\hline Directivity & $6.5555 \mathrm{dBi}$ & $6.6526 \mathrm{dBi}$ & $8.8684 \mathrm{dBi}$ \\
\hline
\end{tabular}

Table IV. Comparative Analysis Of The Proposed Antenna With The Existing Works

\begin{tabular}{|c|c|c|c|}
\hline Parameters & $\begin{array}{c}\text { Proposed } \\
\text { Design }\end{array}$ & $\begin{array}{c}\text { Circular PIFA } \\
\text { Antenna } \\
\text { (Ali,2017) }\end{array}$ & $\begin{array}{c}\text { Multilayered Dipole } \\
\text { Antenna (Hosain, 2012) }\end{array}$ \\
\hline $\begin{array}{c}\text { Dimension } \\
\mathbf{( m m}^{3} \text { ) }\end{array}$ & $\pi^{*}(7.5)^{2 *} 1.58$ & $\pi *(8.5)^{2 *} 1.5$ & $\pi *(10)^{2 *} 2.8$ \\
\hline $\begin{array}{c}\text { Resonant } \\
\text { Frequency }\end{array}$ & $2.4329 \mathrm{GHz}$ & $2.45 \mathrm{GHz}$ & $2.45 \mathrm{GHz}$ \\
\hline $\begin{array}{c}\text { Maximum } \\
\text { Gain(dBi) }\end{array}$ & $-9.4923 \mathrm{dBi}$ & $-14.68 \mathrm{dBi}$ & $-29 \mathrm{dBi}$ \\
\hline $\begin{array}{c}\text { Directivity(dBi } \\
\text { ) }\end{array}$ & $8.8684 \mathrm{dBi}$ & $3.228 \mathrm{dBi}$ & ------- \\
\hline VSWR & 1.098 & ----- & ----- \\
\hline Bandwidth & $61.24 \mathrm{MHz}$ & $53 \mathrm{MHz}$ & $10 \mathrm{MHz}$ \\
\hline
\end{tabular}

\section{Conclusion}

In this paper, a miniaturized implantable multi-facet PIFA antenna with DGS presented. The antenna operates at a frequency of $2.43 \mathrm{GHz}$. The proposed antenna is compact with dimension of $\pi \times 7.5^{2} \times 1.58 \mathrm{~mm}$. The antenna performances with free space, biocompatible material coating, and uterus model layer have been analyzed. The simulation results show that the antenna impedance bandwidth is $61.2 \mathrm{MHz}$. The antenna has stable characteristics in the uterus model layer according to the performance parameters of gain and directivity. 


\section{Declarations}

\section{Conflicts of interest/Competing interests}

The authors have no relevant financial or non-financial interests to disclose.

\section{Authors' contributions}

All authors contributed to the study, conception, design, and simulations. Data collection, analysis, and simulation were initially carried out by Mousume Samad, Md. Mostafizur Rahman and S. M. Shamim. Additional input to analysis and simulation was given by Mousume Samad. All authors contributed to complete the writing and presentation of the whole manuscript.

\section{References:}

1. “Uterine Fibroids Symptoms, Treatment, Causes \& surgery”, Online Available:

https://www.medicinenet.com/uterine_fibroids/article.htm, Accessed: 23-09-2020.

2. "Uterine Fibroids-Diognosis and treatment", Online Available: https://www.mayoclinic.org/diseases-conditions/uterinefibroids/diagnosis-treatment/drc-20354294, Accessed:4-10-2020.

3. Shokry, M. A., \& Allam, A. M. M. A., "Implanted Antenna in Brain". In 2013 Loughborough Antennas \& Propagation Conference (LAPC) (pp. 630-633). IEEE, 2013, November.

4. A. Al-Faruk, K. Abdul Mazed, S. T. Islam and M. L. Rahman, "An On-Body Matched Planar Inverted-F Antenna for Biotelemetry System," 2019 International Conference on Robotics, Electrical and Signal Processing Techniques (ICREST), pp. 553-558, 2019.

5. Wong, K. L. (2004). Compact and broadband microstrip antennas (Vol. 168). John Wiley \& Sons.

6. Sinha, S., Hasan, R.R., Niloy, T.S.R. and Rahman, M.A., "Antenna design and fabrication for biotelemetry applications," International Journal of Electrical and Computer Engineering (IJECE), 11(4), pp.3639-3646, 2021.

7. Soliman, M.M., Chowdhury, M.E., Khandakar, A., Islam, M.T., Qiblawey, Y., Musharavati, F. and Zal Nezhad, E., "Review on Medical Implantable Antenna Technology and Imminent Research Challenges,” Sensors, 21(9), p.3163, 2021.

8. Azzaz-Rahmani, S., Zerrouki, H. and Dekkiche, L., "Novel Microstrip Patch Antenna for implantable medical telemetry devices". Journal of Applied Science and Engineering, 24(6), pp.853-860, 2021. 
9. Singh, G. and Kaur, J., "Design of a compact superstrate-loaded slotted implantable antenna for ISM band applications”. Sādhanā, 46(3), pp.1-10, 2021.

10. M. M. Ali, M. E. I. Bashar and M. K. Hosain, "Circural Planner Inverted-F Antenna for Implantable Biomedical Applications," 2017 2nd International Conference on Electrical \& Electronic Engineering (ICEEE), pp. 1-4, 2017.

11. Nawale, P. A., \& Zope, R. G. "Design and Improvement of Microstrip Patch Antenna Parameters Using Defected Ground Structure”. Diamond, 13, 20-89, 2014.

12. R. Li, Y. Guo, B. Zhang and G. Du, "A Miniaturized Circularly Polarized Implantable Annular-Ring Antenna," in IEEE Antennas and Wireless Propagation Letters, vol. 16, pp. 2566-2569, 2017.

13. N. A. Islam and F. Arifin, "Performance Analysis of a miniaturized implantable PIFA antenna for WBAN at ISM band," 2016 3rd International Conference on Electrical Engineering and Information Communication Technology (ICEEICT), pp. 1-5, 2016.

14. F. Merli, B. Fuchs, J. R. Rosig, and A. K. Skrivervik, "The effect of insulating layers on the performance of implanted antennas," IEEE Transaction on Antennas Propagation, vol. 59, no. 1, pp. 21-31, 2011.

15. Islam, Saiful, and Mst Fateha Samad. "Design and Analysis of a Miniaturized UWB Antenna for Wireless Capsule Endoscopy." 2018 10th International Conference on Electrical and Computer Engineering (ICECE). IEEE, 2018.

16. Hossain, Sharafat, "A simple triple-band antenna for implantable biomedical application." 2017 IEEE Region 10 Humanitarian Technology Conference (R10-HTC). IEEE, 2017.

17. Kumar, Rajeev, Lakhvinder Singh Solanki, and Surinder Singh. "Miniature Archimedean Spiral PIFA Antennas for Biomedical Implantable Devices." 2019 6th International Conference on Signal Processing and Integrated Networks (SPIN). IEEE, 2019.

18. Miran, M. Mohiuddin, and Farhadur Arifin. "Design and Performance Analysis of a Miniaturized Implantable PIFA for Wireless Body Area Network Applications." 2019 International Conference on Robotics, Electrical and Signal Processing Techniques (ICREST). IEEE, 2019.

19. Sultana, Sadia, et al. "Performance analysis of body implantable PIFA at different substrate material." 2017 4th International Conference on Advances in Electrical Engineering (ICAEE). IEEE, 2017. 
20. M. K. Hosain, M. F. Samad, M. M. Mowla, M. Samad. "Multi-Layer Dipole Antenna for Implantable Biomedical Application." International Conference on Electrical, Computer and Telecommunication Engineering. ICECTE, 2012.

21. Parmar, Ajay M., et al. "Sonographic measurements of uterus and its correlation with different parameters in parous and nulliparous women." International Journal of Medical Science and Education 2016.

22. “Density >>IT'IS Foundation”, Online Available: "https://itis.swiss/virtual-population/tissueproperties/database/density/”. Accessed: 7-11-2020.

23. "Dielectric Properties of Body Tissues", Online Available: "http://niremf.ifac.cnr.it/ tissprop/ htmlclie /htmlclie.php”. Accessed: 5-10-2020.

24. Andolf, E., Dahlander, K., \& Aspenberg, "Ultrasonic thickness of the endometrium correlated to body weight in asymptomatic postmenopausal women”. Obstetrics and gynecology, 82(6), 936940 P. 1993.

25. "Person with cancer myometrial thickness, total millimetres $\mathrm{N}[\mathrm{N}]$ ", Online Available:

26. https://meteor.aihw.gov.au/content/index.phtml/itemId/424269/mete orItemView/long', Accessed: 5-10-2020.

27. Wei, S., Gong, Z., An, L., Zhang, T., Dai, H., \& Chen, “Cloprostenol and pregnant mare serum gonadotropin promote estrus synchronization, uterine development, and follicle- stimulating hormone receptor expression in mice”. Genetics and molecular research : GMR, 14(2), 7184- 7195. S. 2015.

28. "RF Safety FAQ |Federal Communications Commission" Online Available: https://www. fcc. gov /engineeringtechnology/electromagnetic-compatibility-division/radio-frequency safety/faq/rf-safety. Accessed: 15-09-2020. 